\title{
Supravalvular Aortic Stenosis as Part of Rubella Syndrome, with Discussion of Pathogenesis ${ }^{\star}$
}

\author{
P. J. VARGHESE, T. IZUKAWA, AND R. D. ROWE \\ From the Department of Pediatrics, The Fohns Hopkins University School of Medicine, and Cardiac Clinic, \\ Children's Medical and Surgical Center, The fohns Hopkins Hospital, Baltimore, Maryland, U.S.A.
}

Gregg (1941) first reported the association of maternal rubella in early pregnancy and congenital malformation. Subsequent authors described additional defects, including cardiac malformation, microcephaly, and deaf mutism (Swan et al., 1943). Persistence of the ductus arteriosus was thought to be the most common cardiac lesion (Campbell, 1961), but the more widespread use of cardiac catheterization and angiocardiography eventually led to an appreciation of the importance of stenoses of pulmonary arteries (Franch and Gay, 1963; Rowe, 1963; Venables, 1964, 1965; Rowe et al., 1966). In two recent reports (Rowe, 1966; Hastreiter et al., 1967) pulmonary artery stenosis was considered to be more frequent than persistence of the ductus arteriosus.

Systemic artery involvement in the rubella syndrome has been described by a few authors. Campbell (1965) described diffuse arterial changes at necropsy in a 3-month-old infant, while Menser et al. (1966) described a child with renal artery stenosis and systemic hypertension secondary to maternal rubella. Reviewing the vascular lesions secondary to maternal rubella at necropsy, Esterly and Oppenheimer (1967) found 8 out of 13 had systemic artery lesions. In angiographic observations in children with cardiovascular lesions due to the rubella syndrome, Hastreiter et al. (1967) found evidence of hypoplasia of the aortic isthmus in 16 per cent of their cases. They were impressed by the absence of disease of the aortic valve and proximal aorta in their series.

The present report describes 2 rubella-affected children with supravalvular aortic stenosis.

Received May 25, 1968.

^ Supported by a United States Public Health Service Grant.

\section{CASE Reports}

Case 1. This Caucasian male infant, birthweight 2552 g., was born on November 12, 1965, after a pregnancy complicated by rubella during the first month. The infant had all the stigmata of a severe congenital rubella.

At the age of 1 month, after an attack of bronchopneumonia and congestive heart failure, he was referred to Johns Hopkins Hospital. Physical examination then showed signs of persistent ductus arteriosus, with pulmonary hypertension and congestive heart failure. An electrocardiogram showed a mean frontal plane axis of $-5^{\circ}$, left atrial enlargement, and biventricular hypertrophy. The heart was moderately enlarged (cardiothoracic ratio 0.60 ) and the lungs were plethoric. Rubella virus was isolated from the throat, urine, eye, and bone-marrow.

At the age of 3 months, cardiac catheterization failed to show any shunt. Systemic arterial oxygen saturation was 94 per cent. Pressures $(\mathrm{mm} . \mathrm{Hg}$ ) were recorded from the right ventricle, 110/0-13, aorta, 113/56, and left atrium, mean 4 . A cine-aortogram showed persistence of a moderate-sized ductus arteriosus.

Two weeks later, a moderately large ductus arteriosus was ligated, after which a systolic thrill was felt in the main pulmonary artery, and signs of pulmonary hypertension persisted after operation. The chest $x$-ray and electrocardiogram were unchanged. Blood calcium and phosphorus levels were normal.

Three weeks after operation, the right ventricular pressure measured $89 / 11 \mathrm{~mm}$. $\mathrm{Hg}$, when the aortic pressure was $112 / 57 \mathrm{~mm}$. Hg. A cine-angiogram showed severe central stenosis of the main pulmonary artery branches with conspicuous post-stenotic dilatation. In the laevogram, an area of constriction above the aortic valve was suspected. The infant's condition deteriorated, and despite further treatment, he died on May 12, 1966.

Necropsy. The heart was enlarged. The valves appeared normal, as did the myocardium. Opaque medium was injected into the pulmonary arteries, and $x$-rays were taken. These showed stenosis of the origin of the main pulmonary artery branches where the lumen was reduced to 50 per cent of the internal diameter. 


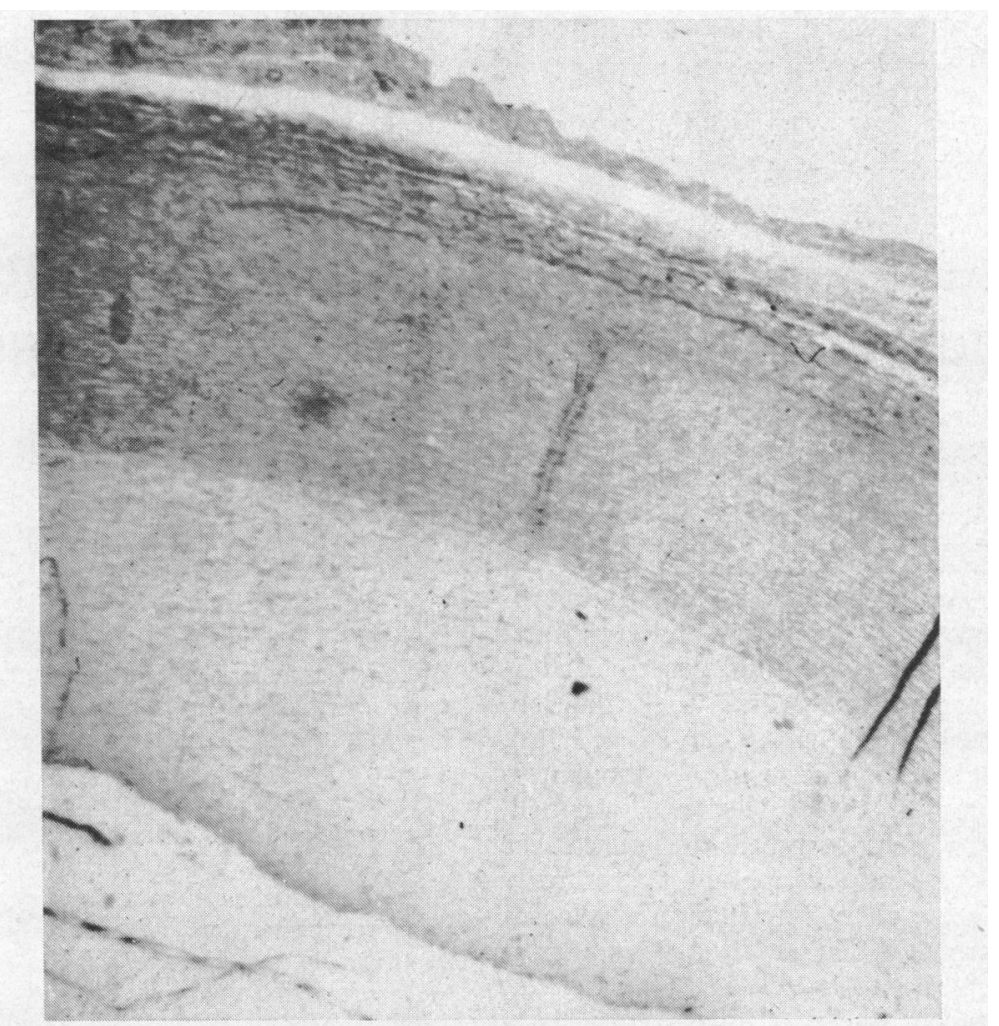

FIG. 1. (Case 1) [Case 9 of Esterly and Oppenheimer, 1967].-Microscopical section of the aorta just above the aortic valve. Note the intimal proliferation.

\begin{abstract}
Microscopical examination. * Intimal proliferation and disruption of elastic tissue, with splitting of internal elastic lamina, was present in the branches of the pulmonary arteries. Intimal proliferation of varying degree was also seen in almost all of the systemic arteries, including the coronary arteries, renal arteries, abdominal aorta, and the thoracic aorta. In the ascending aorta, the intimal changes were marked, and the lumen was significantly narrowed (Fig. 1). Rubella virus was isolated from the cerebrospinal fluid, brain, bone-marrow, spleen, stomach, and thymus.
\end{abstract}

Case 2. This Negro boy was first seen in the Cardiac Clinic at the age of 2 months for evaluation of a heart murmur. The pregnancy was uncomplicated, and the boy, born on November 29, 1964, weighed $3175 \mathrm{~g}$. The child had an uneventful neonatal period except for an upper respiratory tract infection at the age of 4 weeks, for which he was seen at the Cardiac Clinic. Physical examination at that time showed a grade $2 / 6$ ejection systolic murmur, best heard at the base. The murmur was well transmitted to the axilla and apex. The second sound was normally split. An electrocardiogram showed sinus rhythm, a mean frontal plane axis of $+90^{\circ}$, and slight left ventricular dominance. A chest $x$-ray showed

* This material has been reported as Case 9 by Esterly and Oppenheimer (1967). a cardiothoracic ratio of 0.54 , with slight left ventricular enlargement. Studies for rubella antibodies at the age of 1 year were positive. The child has been seen since in the clinic at regular intervals and has been completely asymptomatic. Physical examination at the age of $2 \frac{1}{2}$ years showed a weight of $13 \mathrm{~kg}$. and height of $89 \mathrm{~cm}$. Blood pressure was $100 / 70 \mathrm{~mm}$. Hg. A systolic thrill was palpable in both carotid arteries and in the suprasternal notch. The second sound was normally split and had normal intensity. A grade $2 / 6$ ejection systolic murmur was best heard at the base and was transmitted well to the neck and both axillae. The chest $x$-ray showed a cardiothoracic ratio of 0.60 , and lung vascularity was within normal limits. The electrocardiogram showed sinus rhythm and no evidence of chamber enlargement. Calcium level was $10.3 \mathrm{mg} . / 100 \mathrm{ml}$., and phosphorus level was $6.0 \mathrm{mg} . / 100 \mathrm{ml}$.

At cardiac catheterization, blood oxygen saturations and cine-angiograms revealed no shunts. A peak systolic pressure difference of 6 and $9 \mathrm{~mm}$. $\mathrm{Hg}$ between the main pulmonary artery and left pulmonary artery and right pulmonary artery was noted. On the left side, a peak systolic pressure difference of $15 \mathrm{~mm}$. $\mathrm{Hg}$ was recorded between the aorta and left ventricle. The cardiac output was within normal limits. A cineangiogram from the left ventricle showed an area of constriction just above the aortic valve, indicative of 


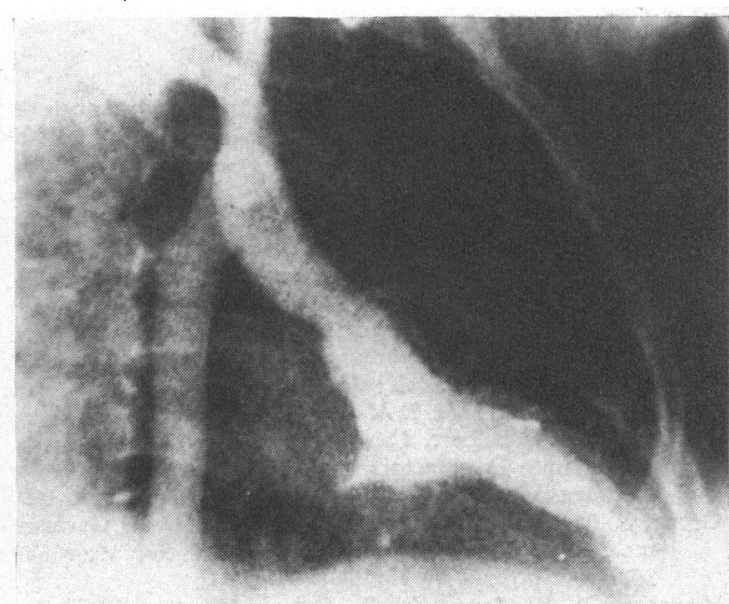

FIG. 2.-Left ventricular cine-angiogram of Case 2 in right anterior oblique projection. Left ventricle and aorta are visualized. Note the shelf-like protrusion just above the aortic valve.

supravalvular aortic stenosis (Fig. 2). The pulmonary arteriogram failed to show any evidence of stenosis.

\section{Discussion}

Even though systemic arterial involvement in rubella has been recorded (Campbell, 1965; Esterly and Oppenheimer, 1967; Menser et al., 1966), supravalvular aortic stenosis has not been described as part of the syndrome. Rowe et al. (1966) suspected supravalvular involvement at angiography in 2 of their patients but were unable to confirm the lesion. The 2 cases of the present communication, seen since the earlier paper, illustrate this type of aortic involvement in the rubella syndrome.

In affected infants, cine-angiograms may show only minimal changes, and at necropsy the gross appearance is often normal. The angiogram in our first case showed only an equivocally suspicious area above the aortic valve, but at later histological examination, intimal proliferation in this region was pronounced (Fig. 1).

Histological lesions of conducting arteries in congenital rubella were described in detail by Campbell (1965). Similar morphological vascular appearances may be seen in a variety of other conditions, such as hypercalcaemia (Rashkind, Golinko, and Arcasoy, 1961), fibromuscular stenosis of renal arteries (Hunt et al., 1962), copper deficiency (Carlton and Henderson, 1963), Friedreich's ataxia (James and Fisch, 1963), and muscular dystrophy (James, 1962). Because the same morphology can result from a variety of stimuli, Rowe et al. (1966) speculated that a common factor, such as an inter- ference with muscle and elastin formation, might be operative.

There are many morphological similarities between the vascular lesions of rubella and those of idiopathic infantile hypercalcaemia of infancy. A frequent late result of infantile hypercalcaemia is fairly marked supravalvular aortic and marked bilateral pulmonary arterial stenosis (Antia et al., 1967; Beuren et al., 1964; Garcia et al., 1964). During infancy, however, while the aortic lesion is severe, the pulmonary arteries are only minimally affected. On the other hand, in rubella, pulmonary artery involvement is by far the most common vascular lesion (Rowe, 1966; Hastreiter et al., 1967) and is usually extensive and obvious early in infancy, whereas supravalvular aortic stenosis is not only rare but is minimal.

Since there is a difference in the vascular involvement in rubella and infantile hypercalcaemia, consideration is needed of factors that may modify the clinical expression of the vascular defect. In rubella cardiovascular disease, there are reasonable grounds to believe that an essential element in pathogenesis is the presence of rubella virus in the cells of the vessel. In the supravalvular aortic stenosis syndrome related to infantile hypercalcaemia, the aetiological factors are less clear, but present evidence incriminates some disturbance of vitamin D calcium homeostasis (Antia et al., 1967). In rubella cases an unusual opportunity may exist for concentration of virus in pulmonary arteries in foetal life. In a low flow and low velocity system such as the foetal pulmonary circuit, a situation may develop where either the clearance rate of virus particles is reduced or endothelial transfer of virus may be enhanced. Rubella virus retards the growth of infected cells without necessarily affecting their morphological characteristics (Naeye and Blanc, 1965), so that the number of vascular smooth muscle cells might be reduced in congenital rubella in a way such as has been shown for striated muscle in this disorder (Cheek, 1968). A reduced number of cells in the pulmonary artery divisions could result in hypoplasia of the branches, and these changes could be magnified during the postnatal period by haemodynamic factors such as increasing flow. On the other hand, in the foetal systemic circuit, a relatively high velocity flow may minimize the concentration of virus in conducting arteries except in areas where turbulence might permit invasion, as for example, at the aortic root or in renal arteries. Postnatally, the progression of the lesion seems to be determined by haemodynamic factors rather than continued excretion of virus by the infant.

It might be expected that in a metabolic disorder such as infantile hypercalcaemia the effects on conducting vessels initially might be uniform, and that 
the expression of the disease would more likely be influenced by postnatal haemodynamics. This would support the findings in vitamin $\mathrm{D}$ intoxication in older children or animals (Friedman and Roberts, 1966; Gillman and Gilbert, 1956) where the worst damage is at points of stress in the ascending aorta and other systemic branches. Though damage to the matrix of the vessel wall is probably similar in both circulations in infantile hypercalcaemia, the development of pulmonary arterial stenosis appears to be slow. This difference in the clinical expression in two circuits could be explained if hypercalcaemia damage were principally postnatal, when the pressure in the pulmonary artery is lower than in the aortic artery.

\section{SUMMARY}

Two infants with supravalvular aortic stenosis, as part of the congenital rubella syndrome, are reported. Rubella virus was isolated from one, and the other showed significant increase in titre for rubella antibodies. Angiographic appearances were conclusive in one case, and the other, at necropsy, showed proliferation and splitting of internal elastic lamina just above the aortic valve.

Morphological appearance of the arterial lesions in congenital rubella and infantile hypercalcaemia is similar, but the distribution of the arterial lesion is different. Prenatal and postnatal factors appear to influence the clinical expression of the arterial involvement in these disorders. Haemodynamic factors, such as flow, velocity, and pressure, may play a significant role in pathogenesis.

\section{REFERENCES}

Antia, A. U., Wiltse, H. E., Rowe, R. D., Pitt, E. L., Levin, S., Ottesen, O. E., and Cooke, R. E. (1967). Pathogenesis of the supravalvular aortic stenosis syndrome. $\mathcal{F}$. Pediat., 71, 431.

Beuren, A. J., Schulze, C., Eberle, P., Harmjanz, D., and Apitz, J. (1964). The syndrome of supravalvular aortic stenosis, peripheral pulmonary stenosis, mental retardation and similar facial appearance. Amer. f. Cardiol., $13,471$.

Campbell, M. (1961). Place of maternal rubella in the aetiology of congenital heart disease. Brit. med. F., 1, 691.

Campbell, P. E. (1965). Vascular abnormalities following maternal rubella. Brit. Heart f., 27, 134.

Carlton, W. W., and Henderson, W. (1963). Cardiovascular lesions in experimental copper deficiency in chickens. f. Nutr., 81, 200.

Cheek, D. (1968). Muscle cell growth in abnormal children. In Human Growth, pp. 354-55. Ed. by D. Cheek. Lea and Febiger, Philadelphia.
Esterly, J. R., and Oppenheimer, E. H. (1967). Vascular lesions in infants with congenital rubella. Circulation, 36, 544.

Franch, R. H., and Gay, B. B. (1963). Congenital stenosis of the pulmonary artery branches: a classification, with postmortem findings in two cases. Amer. F. Med., 35, 512.

Friedman, W. F., and Roberts, W. C. (1966). Vitamin D and the supravalvar aortic stenosis syndrome: the transplacental effects of vitamin D on the aorta of the rabbit. Circulation, 34, 77.

Garcia, R. E., Friedman, W. F., Kaback, M. M., and Rowe, R. D. (1964). Idiopathic hypercalcemia and supravalvular aortic stenosis: documentation of a new syndrome. New Engl. F. Med., 271, 117.

Gillman, J., and Gilbert, C. (1956). Calcium, phosphorus and vitamin $\mathrm{D}$ as factors regulating the integrity of the cardiovascular system. Exp. Med. Surg., 14, 136.

Gregg, N. M. (1941). Congenital cataract following German measles in the mother. Trans. ophthal. Soc. Aust., 3, 35.

Hastreiter, A. R., Joorabchi, B., Pujatti, G., van der Horst, R. L., Patacsil, G., and Sever, J. L. (1967). Cardiovascular lesions associated with congenital rubella. f. Pediat., 71, 59.

Hunt, J. C., Harrison, E. G., Jr., Kincaid, O. W., Bernatz, P. E., and Davis, G. D. (1962). Idiopathic fibrous and fibromuscular stenoses of the renal arteries associated with hypertension. Proc. Mayo Clin., 37, 181.

James, T. N. (1962). Observations on the cardiovascular involvement, including the cardiac conduction system, in progressive muscular dystrophy. Amer. Heart f., 63, 48.

$\longrightarrow$, and Fisch, C. (1963). Observations on the cardiovascular involvement in Friedreich's ataxia. Amer. Heart f., 66, 164.

Menser, M. A., Dorman, D. C., Reye, R. D. K., and Reid, R. R. (1966). Renal-artery stenosis in the rubella syndrome. Lancet, 1, 790.

Naeye, R. L., and Blanc, W. (1965). Pathogenesis of congenital rubella. F. Amer. med. Ass., 194, 1277.

Rashkind, W. J., Golinko, R., and Arcasoy, M. (1961). Cardiac findings in idiopathic hypercalcemia of infancy. f. Pediat., 58, 464.

Rowe, R. D. (1963). Maternal rubella and pulmonary artery stenoses: report of 11 cases. Pediatrics, 32, 180.

- (1966). Cardiovascular lesions in rubella. Letter to the Editor. F. Pediat., 68, 147.

—, Mehrizi, A., Elliott, H. L., and Neill, C. A. (1966), Cardiovascular disease in the rubella syndrome. In The Heart and Circulation in the Newborn and Infant, p. 180. Ed. by D. E. Cassels. Grune and Stratton, New York.

Swan, C., Tostevin, A. L., Moore, B., Mayo, H., and Block, G. H. B. (1943). Congenital defects in infants following infectious diseases during pregnancy, with special reference to the relationship between German measles and cataract, deaf-mutism, heart disease and microcephaly, and to the period of pregnancy in which the occurrence of rubella is followed by congenital abnormalities. Med. F. Aust., 2, 201.

Venables, A. (1964). "The syndrome of pulmonary stenosis following maternal rubella," paper read before the Paediatric Society of Victoria, Melbourne, November 13, 1963. Med. F. Aust., 1, 1011.

- (1965). The syndrome of pulmonary stenosis compli-cating maternal rubella. Brit. Heart f., 27, 49. 